\title{
Antiphospholipid syndrome in a patient with rapidly progressive fibrosing alveolitis
}

\author{
Andrew D Kelion, John R Cockcroft, James M Ritter
}

\begin{abstract}
Summary
The antiphospholipid syndrome is a thrombotic disorder which can occur in a primary form or more classically in systemic lupus erythematosus. An association between cryptogenic fibrosing alveolitis and the antiphospholipid syndrome has not previously been reported. We describe a patient with severe cryptogenic fibrosing alveolitis who developed pulmonary embolism and myocardial infarction in the presence of antiphospholipid antibody. The case also illustrates that worsening respiratory function may represent superimposition of one lung pathology on another, and may not simply be a deterioration of the pre-existing disease.
\end{abstract}

Keywords: antiphospholipid syndrome, fibrosing alveolitis

\section{Introduction}

The antiphospholipid syndrome is a disorder involving both arterial and venous thrombosis in association with antibodies directed against phospholipids. It was first described in patients with systemic lupus erythematosus (SLE), ${ }^{1}$ subsequently in lupus variants such as discoid lupus and Sjogren's syndrome, and more rarely in rheumatoid arthritis and primary vasculitis. ${ }^{2}$ It has not, however, been described in association with cryptogenic fibrosing alveolitis. The following case demonstrates such an association in a patient whose worsening dyspnoea was due to one life-threatening aetiology superimposed on another.

Department of

Clinical

Pharmacology,

UMDS, Guy's

Hospital, London SE1

9RT, UK

AD Kelion

JR Cockcroft

JM Ritter

Correspondence to

Professor JM Ritter,

Department of Clinical

Pharmacology, UMDS,

Medical School Building,

Guy's Hospital, London SE 1

9RT, UK

Accepted 27 October 1994

\section{Case report}

A 58-year-old woman was admitted to hospital with a six-week history of progressive dyspnoea and a non-productive cough for two weeks. She had been fit and well in the past, except for possible tuberculosis in childhood. There was no history of skin or joint problems, or recurrent abortions. She was a lifelong nonsmoker and was the landlady of a pub. She kept two dogs and a cat, but no birds.

She had pronounced flushing of the face with no other skin changes. There was finger clubbing. She was apyrexial with a heart rate of 90 beats/min and a blood pressure of 160/
$80 \mathrm{mmHg}$. The jugular venous pressure was not elevated. She had a right ventricular heave, a loud pulmonary component of the second heart sound, and an ejection systolic murmur at the lower left sternal edge, findings consistent with pulmonary hypertension. There were fine inspiratory crackles over both lower tubes.

The chest radiograph showed severe interstitial shadowing over most of the left lung field, with lesser basal shadowing on the right. Arterial blood gases with the patient breathing air were $\mathrm{pO}_{2} 9.2 \mathrm{kPa}, \mathrm{pCO}_{2} 5.2 \mathrm{kPa}, \mathrm{pH} 7.45$. A ventilation-perfusion lung scintigram did not suggest pulmonary embolism (figure). Serology revealed the presence of antinuclear antibody in both IgG and IgM forms at a titre of $1 / 160$; this gave a diffuse homogeneous staining pattern. Anti-double-stranded DNA antibody and other immunological markers for SLE and other connective tissue diseases were not detected. Antiphospholipid antibody was also present in the IgG form at a titre of 26 units (moderately positive; Lupus Research Laboratory, St Thomas's Hospital, London); lupus anticoagulant was not detected. Bronchoscopy was unremarkable, as was the result of broncheoalveolar lavage. Lung function tests revealed a restrictive defect: $\mathrm{FEV}_{1}$ 1.0-1.1 (predicted 1.9-2.7), FVC 1.1 (2.3-3.1), FEV $1.0 /$ FVC $100 \%$ KCO 1.2 (1.5-2.5).

A diagnosis of cryptogenic fibrosing alveolitis was made. She was commenced on prednisolone $60 \mathrm{mg}$ and improved dramatically within 48 hours. She was discharged on a reducing course of prednisolone. Six weeks later she was readmitted to hospital with a two-day history of worsening dyspnoea. She was by now taking $10 \mathrm{mg}$ prednisolone daily. On examination she was very distressed and cyanosed. She was apyrexial, with a heart rate of 120 beats/min, a blood pressure of $160 /$ $80 \mathrm{mmHg}$, and a respiratory rate of 60 breaths/ min.

The chest radiograph on admission showed dense reticular shadowing in both lower zones. The arterial blood gases with the patient breathing $100 \%$ oxygen were $\mathrm{pO}_{2} 6.2 \mathrm{kPa}$, $\mathrm{pCO}_{2} 5.7 \mathrm{kPa}, \mathrm{pH} 7.26$, bicarbonate $19 \mathrm{mmol} / \mathrm{l}$, oxygen saturation $76 \%$. The electrocardiograph (ECG) was unremarkable. Renal function was normal. Routine haematology was as follows: haemoglobin $15.0 \mathrm{~g} / \mathrm{dl}$, white cell count $19.0 \times 10^{9} / 1$ (neutrophil leucocytosis), platelet count $157 \times 10^{9} / 1$. Clotting times were all within the normal range, as were levels of 


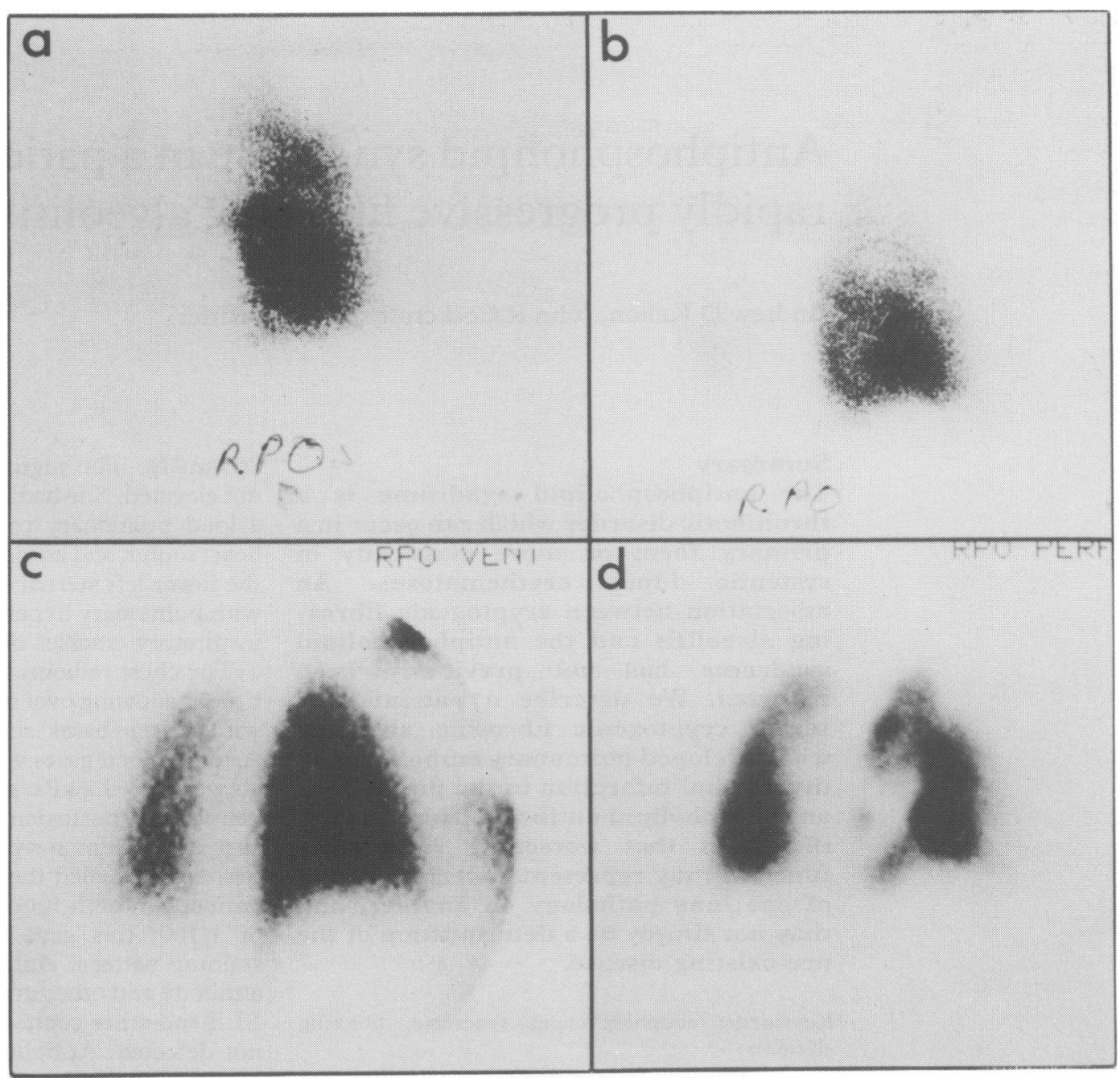

Figure Ventilation perfusion lung scans. At initial presentation, ventilation (a) and perfusion (b) scans were matched whereas subsequently there were un-matched defects in the perfusion scan (d) compared with the ventilation scan (c). All views were right posterior oblique.

antithrombin 3, protein $\mathrm{C}$, and protein $\mathrm{S}$. The erythrocyte sedimentation rate was $32 \mathrm{~mm} / \mathrm{h}$, and the C-reactive protein titre was $2.9 \mathrm{mg} / \mathrm{dl}$ (normal range $<1 \mathrm{mg} / \mathrm{dl}$ ).

The pulse oximeter reading on high-flow oxygen remained $75-80 \%$ at rest, but dropped dramatically on the slightest exertion. Increased doses of steroid were administered intravenously (methylprednisolone $500 \mathrm{mg}$ daily), and intravenous cefotaxime and oral erythromycin were given for a possible community-acquired pneumonia. A ventilation-perfusion lung scintigram was performed. This showed widespread segmental and subsegmental perfusion defects in both lung fields, with a normal ventilation scan: these appearances were strongly suggestive of pulmonary embolism (figure). She was treated with intravenous heparin.

She became progressively more exhausted, and by the 5th hospital day had a temperature of $38^{\circ} \mathrm{C}$ and an oxygen saturation of $68 \%$. The platelet count had fallen to $64 \times 10^{9} / 1$. The ECG now showed changes characteristic of an acute inferior myocardial infarction. She was intubated and ventilated in the intensive care unit. The next day an open lung biopsy was performed to obtain an histological diagnosis as her lung function was too poor to allow bronchoscopic biopsy $\left(\mathrm{pO}_{2} 13 \mathrm{kPa}, \mathrm{pCO}_{2} 14 \mathrm{kPa}\right.$ and pH 6.90 on pressure control ventilation with an inspired oxygen concentration of $70 \%$ ). Anticoagulation with heparin proved difficult to control, and postoperatively bleeding occurred from the chest drain. The activated partial thromboplastin time was found to be $148 \mathrm{~s}$ (normal range 29-39 s), and intravenous epoprostenol was substituted for heparin. Histology of the lung biopsy showed extensive interstitial fibrosis, consistent with fibrosing alveolitis, with superimposed pneumonic changes. Blood cultures were repeatedly negative, as was serology for atypical organisms. Intravenous cyclophosphamide was added to the methylprednisolone.

She remained in deep coma despite the withdrawal of sedation. CT scan of the brain showed a massive intracerebral haemorrhage into the right parietal lobe with severe midline shift and herniation of the cerebellar tonsils through the foramen magnum. She deteriorated rapidly and died.

Post-mortem examination confirmed massive right intracerebral haemorrhage that was felt to be the immediate cause of death. The lungs were both firm and solid with confluent 
Table Diseases associated with antiphospholipid antibodies

\begin{tabular}{|c|c|c|}
\hline Rheumatological & Haematological & Other \\
\hline $\begin{array}{l}\text { Systemic lupus erythematosus } \\
\text { Discoid lupus } \\
\text { Rheumatoid arthritis } \\
\text { Vasculitis } \\
\text { Systemic sclerosis, polymyositis, } \\
\text { 'overlap syndromes' } \\
\text { Juvenile chronic arthritis } \\
\text { Sjögren's syndrome } \\
\text { Psoriatic arthropathy } \\
\text { Raynaud's phenomena } \\
\text { Behçet's disease } \\
\text { Acute rheumatic fever }\end{array}$ & $\begin{array}{l}\text { Autoimmune haemolytic anaemia and } \\
\text { thrombocytopaenic purpura } \\
\text { Lymphomas and leukaemias } \\
\text { Waldenström's macroglobulinaemia }\end{array}$ & $\begin{array}{l}\text { Liver disease } \\
\text { Endocrine disorders - } \\
\text { hypothyroidism \& Addison's disease } \\
\text { Drugs - oral contraceptives, drug-induced } \\
\text { lupus } \\
\text { Ulcerative colitis }\end{array}$ \\
\hline
\end{tabular}

whitish nodules. Histology showed interstitial fibrosis with a superimposed acute purulent bronchopneumonia; no organisms were seen with several special stains. There was peripheral segmental thromboembolism in the right lung, with bilateral deep vein thrombosis in the calves and thighs. There was a recent posterolateral subendocardial myocardial infarction, with minimal coronary atheromatous disease. No vasculitic process was evident in any of the tissues studied. These findings confirmed the diagnosis of rapidly progressive cryptogenic fibrosing alveolitis associated with thromboembolic disease, in the presence of the antiphospholid antibody. Current criteria for the classification of the antiphospholipid syndrome require positivity for antiphospholipid antibodies to be confirmed on two occasions, six to eight weeks apart. ${ }^{3}$ However, in this case the patient died before a second estimation of antiphospholipid antibodies could be made and unfortunately no stored serum was available to allow for postmortem determination.

\section{Discussion}

The antiphospholipid syndrome can present in a variety of ways depending on the artery or vein affected by thrombosis. Deep venous thrombosis, recurrent pulmonary embolism, and myocardial infarction, all of which occurred in the patient described above, are common modes of presentation.

There was no evidence of pulmonary embolism at the original presentation, and the development of multiple pulmonary emboli probably led to the rapid clinical deterioration

1 Bowie EJW, Thompson JH Jr, Pascuzzi CA, Owen CA Jr. Thrombosis in systemic lupus erythematosus despite circulating anticoagulants. $\mathcal{F}$ Lab Clin Med 1963; 62: 416-30. 2 Hughes GRV. The antiphospholipid syndrome: ten years on. Lancet 1993; 342: 341-4.

3 Harris EN. Syndrome of the black swan. Br $\mathcal{F}$ Rheumatol 1987; 26: 324-5.

4 Conley CL, Hartmann RC. A haemorrhagic disorder caused by circulating anticoagulant in patients with disseminated lupus erythematosus. $\mathcal{F}$ Clin Invest 1952; 31: 621-2. and the final admission. Although the histological findings suggested a pneumonic process superimposed on the fibrosing alveolitis, special stains failed to reveal any causative microorganism and repeated cultures were negative. The myocardial infarction may have precipitated admission to the intensive care unit. Even without these thrombotic insults, our patient's long-term prognosis would have been very poor given the severity of her underlying lung pathology.

The ultimate cause of death was a massive intracerebral bleed. Interestingly, the lupus anticoagulant in association with false positive syphilis serology (the original marker for antiphospholipid antibody) was first described in two SLE patients with a bleeding disorder and a prolonged prothrombin time. ${ }^{4}$ Subsequently it has become clear that thrombosis and not haemorrhage is by far the more important effect of the antiphospholipid antibody. ${ }^{1}$

The antiphospholipid syndrome is classically associated with SLE and lupus variants, and has rarely been described in rheumatoid arthritis and vasculitis (table). Our patient had histologically proven fibrosing alveolitis, but no features of SLE. Antinuclear antibody is a non-specific serological marker, and its presence is well described in cryptogenic fibrosing alveolitis, occurring in $21-42 \%$ of cases. ${ }^{5,6}$ To our knowledge, this is the first report of an association between cryptogenic fibrosing alveolitis and the antiphospholipid syndrome.

We gratefully acknowledge the help of Dr Su Ramachandra, Senior Registrar in Histopathology.

5 Chapman JR, Charles PJ, Venables PJ, et al. Definition and clinical relevance of antibodies to nuclear ribonucleoprotein and other nuclear antigens in patients with cryptogenic fibrosing alveolitis. Am Rev Respir Dis 1984; 130: 439-43. 6 Holgate ST, Haslam P, Turner-Warwick M. The significance of antinuclear and anti-DNA antibodies in cryptogenic fibrosing alveolitis. Thorax 1983; 38: 67-70. 